\title{
Environmental feasibility study for deployment and construction of mobile gas turbine power plants in urbanized areas
}

\author{
Fedor Bryukhan ${ }^{1, *}$ \\ ${ }^{1}$ Moscow State University of Civil Engineering, Yaroslavskoe shosse, 26, Moscow, 129337, Russia
}

\begin{abstract}
In the view of current electrical shortage in some regions of Russia, mobile gas turbine power plants (MGTPP) have become urgent in recent years. Usually they are used as back-up power sources to cover peak loads in power networks and to ensure uninterrupted power supply to consumers. This paper deals with environmental feasibility study for deployment and construction of the MGTPP in an urban setting. Technogehic factors of the MGTPP impact on the environment have been assessed and possibility of the MGTPP deployment at various sites in different regions of Russia has been identified. The necessity of using the technology of water injection into the gas turbine units combustion chamber to suppress nitrogen oxides in some cases is mentioned. Quantitative assessments of the MGTPP technogehic impact on the environment components have been performed using standard techniques. The calculations have revealed that the MGTPP specifications ensure the levels of technogehic impacts within the standard limits. The results have ensured preparation of pre-design and design documentation related to protection of the environment against the MGTPP complex technogehic impact.
\end{abstract}

\section{Introduction}

One of the promising areas of power generation in an urban setting is the development of mobile gas turbine power engineering. The basis of such power engineering are mobile gas turbine power plants (MGTPP) operated on the basis of the power generating units equipped with gas turbine units (GTU) that burn kerosene or natural gas [1,2]. Usually the MGTPP are operated as back-up power sources to cover peak loads in power networks and to ensure uninterrupted power supply to consumers in emergencies.

GTU-based power generation technologies ensure [2, 3]:

- relatively low economic costs for the MGTPP construction as compared to conventional thermal power plants;

- easy maintenance of the MGTPP;

- relatively low level of MGTPP complex environmental impact.

*Corresponding author: pniiis-gip@mail.ru 
An optimal operation mode for the MGTPP is standby condition and state of readiness to be connected to the power supply in case of power shortage. Therefore the total duration of the MGTPP operation within a year is insignificant and is typically 100-200 hours per year [2].

The MGTPP have been widely used in Russia in the last decade. The reason for their mass construction is power shortage in some regions. With the commissioning of new stationary power plants in some regions, the MGTPP previously operated in those regions are dismantled and transported to other regions, as necessary, where there is power shortage. Currently, there are 18 MGTPP power generating units operated in Russia with a total capacity of $405 \mathrm{MW}$.

Considering the acuteness of environmental safety of power generating facilities being under construction in an urban setting, MGTPP deployment and construction planning requires appropriate environmental feasibility study [4, 5]. This article deals with assessment of environmental safety of MGTPP construction and operation.

\section{MGTPP and environment}

Power substation areas are typically used as construction sites for the MGTPP, since such deployment of the MGTPP requires high-voltage lines to supply power to electric networks.

The environmental feasibility study for the MGTPP construction consists in the study of the MGTPP technogehic impact on environmental components and in the development of proposals to prevent or to mitigate such impacts and related social, economic and other consequences. The main result of such study is to develop materials for the MGTPP environmental impact assessment (EIA) and the list of measures for environmental protection.

The power generating unit of a mobile power plant consists of a GTU comprising a gas generator with a power turbine, power generator and auxiliary systems. The GTU output voltage is $10.5 \mathrm{kV}$, rated power is $25.5 \mathrm{MVA}$, frequency is $50 \mathrm{~Hz}$. The control unit comprises an electric unit and automated process control system elements. The GTU is designed on the basis of the Pratt \& Whitney Power Systems aircraft gas turbine engine FT8 [2]. Power is usually generated as a result of combusting aviation kerosene with a low content of tar and sulfur. GTU turbine cooling uses air. Flue gases are emitted from the chimney of $10.3 \mathrm{~m}$ high.

Previously, it has been found that main MGTPP negative impacts on the environment are air pollution and noise. Considering this fact the environmental feasibility study for construction at a new site includes:

- collection and analysis of published and library materials on the state of the environment near the construction site;

- determination of design air pollution and acoustic fields characteristics;

- assessment of the amount of wastewater and solid wastes;

- qualitative assessment of soil and geological environment damage;

- development of proposals for protection of environment and population against the MGTPP impact considering engineering surveys.

\section{Results and discussion}

The environmental feasibility study for the MGTPP deployment and construction was performed for the following sites: Pushkino (Moscow region), Rublevo (Moscow city), Kyzyl (Republic of Tyva), Sayanogorsk (Republic of Khakassia), Kodinsk (Krasnoyarsk krai), Psou River, PATP-6, TPP (Sochi city) [1, 2]. Mobile power plants construction 
projects considering the obtained justifying results were performed, the plants were built, and dismantled after the planned period of operation.

The MGTPP technogehic impact on the environment occurs during construction and installation works, as well as during their operation.

\subsection{Stage of construction works}

At the stages of preparation for construction, construction and dismantling, the MGTPP has the following main impacts:

- air pollution during operation of construction equipment;

- noise impact during operation of construction equipment;

- contamination of surface and groundwater;

- damage to geological environment;

- generation of construction wastes.

On the basis of climatic temperature and wind data, as well as background values of pollutant concentration in the air, the fields of their maximum one-time concentrations during construction were calculated using the technique [6]. It was found that air pollution during construction caused with road construction equipment and vehicles, painting and welding, was negligible.

Noise impact during construction occurs due to construction equipment operation. The studied sites were located from the nearest residential houses far enough, and the construction works took a small period of time (30-40 days). Therefore, the noise impact was assessed to be insignificant and not requiring any adjusted quantitative assessment.

The water used for the household needs was brought from offsite. Its consumption for the entire period of construction was insignificant and only a few $\mathrm{m}^{3}$. Accordingly, the amount of wastewater was negligible as well.

The construction works include pit excavation, backfilling and leveling of the site, site surface drainage, technical and biological reclamation stage. This is accompanied by the damage to topsoil, changes in the site relief and surface rain water runoff. The calculations showed that the overall soil balance during grading, excavation and backfilling was kept intact, therefore there was no need to remove it from the sites. To keep the topsoil it was planned to be removed and stored prior to the excavation, and upon completion backfilled to the areas free from construction facilities and internal passages followed by grass cover remediation. The area free from road and process surfaces was planned to be covered with $0.1 \mathrm{~m}$ thick crushed stone and lawns with grass sowing.

Estimated amount of waste generated during construction period was from 4 to $12 \mathrm{t}$, which were planned to be removed outside the sites.

Thus, the technology of the MGTPP construction and operation has no significant impact on the state of atmospheric air, surface and groundwater, geological environment and does not generate significant noise.

\subsection{Operation stage of the MGTPP}

Major environmental impacts during operation of the MGTPP include:

- air pollution;

- noise impact during GTU operation;

- contamination of surface and groundwater;

- generation of waste.

The major source of GTU pollutant emissions is an exhaust device, which releases combustion products (nitrogen oxides, sulfur dioxide, carbon monoxide, hydrocarbons, suspended solids) to the atmosphere. The assessments of nitrogen oxide and dioxide 
concentration fields considering their background values point out the necessity of suppressing the nitrogen oxides in some sites using denox technology (stands for the word combination "de $\mathrm{NO}_{\mathrm{x}}$ ") [7]. This technology involves the injection of desalinated water into the GTU combustion chamber. The necessity of suppressing the nitrogen oxides appeared on the sites Pushkino (Moscow region), Rublevo (Moscow city), Psou River, PATP-6, TPP (Sochi city).

Another source of air pollution - emissions of kerosene vapors during refilling of the MGTPP kerosene fuel tanks. The calculations have shown that in all the sites the ground level concentrations of the pollutants emitted into the atmosphere during the MGTPP operation do not exceed maximum allowable values for residential area.

To assess the noise impact, acoustic calculation according to the [2] was performed. The results of calculations of noise equivalent level in apartment block reference points for all surveyed sites showed no excess of allowable noise level.

During the MGTPP operation water is used for the following purposes:

- for drinking needs of personnel;

- for periodic washing of equipment;

- for the use of the denox technology (if necessary).

The MGTPP is supplied from public waterworks system or artesian well. Industrial waste water includes periodic and emergency runoffs. The former include storm water, wastewater from fuel tanks and GTU gas-air section washing, the emergency runoffs include fuel spills.

To prevent surface water contamination with rain and snowmelt runoffs, the project provides for arrangement of the relief where the general slope of the site is made in the direction opposite to the natural water bodies. The MGTPP site slope is made to allow rain and snowmelt water to flow into the drainage channel. The latter are the ditches of $0.5 \mathrm{~m}$ deep lined with hygroscopic material and filled with crushed stone to settle and filter wastewater.

Waste during the MGTPP operation includes: used and rejected mercury lamps, amenity room's garbage, spent aviation and transformer oil, cleaning cloth, site sweepings. Rules of the MGTPP operation provide for periodic waste removal.

Detailed calculations show that, subject to observation of the MGTPP operation and waste handling rules the MGTPP does not have a significant pollution impact on surface and groundwater. According to the results of the environmental studies conducted at the sites listed above, the EIA materials were prepared and environmental protection measures were developed for the areas adjacent to the MGTPP.

\section{Conclusions}

- The complex analysis of environmental safety of the MGTPP deployment projects in various regions of Russia was conducted taking into account the Pratt \& Whitney Power Systems FT8 turbine-based power generation technology.

- The calculations of the MGTPP impact on the environment components during construction and operation of their power generating units revealed that the MGTPP specifications ensure the levels of technogehic impacts within the standard limits.

- The results ensured preparation of the EIA materials and development of measures to protect the environment of the areas adjacent to the MGTPP. 


\section{Acknowledgments}

The author thanks Dr E.A. Cheremikina, Head of the Ecological Department of the RosEnergoProekt Institute (Moscow) for useful consultations.

\section{References}

1. F.F. Bryukhan, I.O. Kos'kin, Proceedings of the Moscow State University of Civil Eng. 5, 143-149 (2012)

2. A.F. Bryukhan, E.A. Cheremikina, Mobile Peak-Load Gas Turbine Power Plants and the Environment (Forum Publishing House, Moscow, 2011)

3. K. Hanjalic, R. Van Van De Krol, A. Lekic (Eds.), Sustainable energy technologies (Springer, Dordrecht, 2008)

4. J.M. Beer, Prog. Energy Combust. Sci. 33, 2 (2007)

5. S.A. Jozi, A.A. Pouriyeh, Chem. Ind. Chem. Eng. Q. 17, 4 (2011)

6. OND-86. Methods of calculation of air polluting concentrations emitted by industrial facilities (Gidrometizdat Publishing House, Leningrad, 1987)

7. L. Smith, H. Karim, M. Castaldi et al., J. Eng. Gas Turbines Power 127, 1 (2005) 